\title{
Avaliação de Soldas Dissimilares com a \\ Técnica da Dupla Camada Utilizando os \\ Arames-Eletrodos AWS ER 316L e ER \\ NiCrMo-3 sobre o Aço ASTM A182 F22
}

\section{Evaluation of Dissimilar Welds with the Temper-bead \\ Technique Using ER 316L and ER NiCrMo-3 Electrodes on ASTM A182 F22 Steel}

\author{
Humberto Vinicius Muñoz Aguirre ${ }^{1}$, Felipe Ribeiro Teixeira ${ }^{1}$, \\ Carlos Alberto Mendes da Mota ${ }^{1}$, Alexandre Saldanha do Nascimento ${ }^{1}$
}

\footnotetext{
${ }^{1}$ Universidade Federal do Pará, PPGEM/GETSOLDA/UFPA, CEP: 66075-110, Rua Augusto Corrêa No 1, Belém, PA, Brasil.

E-mail: humbertoaguirre23@yahoo.com.br, teixeira.304@hotmail.com, cmota@ufpa.br, saldanha77@yahoo.com.br
}

\section{RESUMO}

Um adequado procedimento para a soldagem de materiais dissimilares deve prever o amanteigamento do bisel através da técnica da dupla camada, de modo a estabelecer uma barreira térmica capaz de minimizar os problemas de fragilização da junta. A interface do amanteigamento nessas soldas é apontada como a região mais crítica da junta devido à presença de fases duras, normalmente encontradas na região grosseira da zona afetada pelo calor (ZAC) e próximo da linha de fusão. O presente trabalho visa investigar a viabilidade das técnicas de Higuchi e Higuchi Modificado para a seleção dos parâmetros operacionais para a soldagem controlada pela técnica da dupla camada, em termos do revenimento da ZAC com granulação grosseira da primeira camada depositada sobre um aço ARBL. Os revestimentos foram depositados com os arames-eletrodos o ER NiCrMo-3 e o ER 316L, os quais utilizaram o processo GMAW (Gas Metal Arc Welding) com corrente pulsada e com corrente convencional, respectivamente. O aço ARBL (Alta Resistência Baixa Liga) ASTM A182 F22 foi utilizado como substrato. Os resultados mostraram uma redução no nível de microdureza da ZAC da primeira camada por meio da utilização da técnica da dupla camada. Contudo, o nível de revenimento alcançado ainda é insuficiente ao ponto de eliminar completamente o uso de Tratamento Térmico de Alívio de Tensões (TTAT).

Palavras-chave: Soldagem dissimilar; técnica da dupla camada; teste de Higuchi.

\begin{abstract}
An adequate procedure for dissimilar welding must use the buttering of the bevel through the temper-bead technique, in order to establishing a thermal barrier capable to minimize the joint embrittlement. The buttering interface in these welds is indicated as the most critical region of the joint due to the presence of hard phases, which are often found in the coarse region of the heat affected zone (HAZ) and near the fusion line. The present work aims to investigate the feasibility of the Higuchi and Modified Higuchi techniques for the selection of operational parameters for controlled welding by the temper-bead technique, concerning the tempering the HAZ with coarse grains of the first layer deposited on an HSLA (High Strength Low Alloy) steel. The weld overlays were deposited by the combination of two wires, the ER NiCrMo-3 and the ER 316L, which used the GMAW (Gas Metal Arc Welding) process with pulsed current and with conventional current, respectively. The ASTM A182 F22 HSLA steel was used as base metal. The results showed a reduction in the microhardness level of the first layer HAZ by using the temper-bead technique. However, the tempering level achieved is still insufficient to eliminate the use of postweld heat treatment (PWHT).
\end{abstract}

Key-words: Dissimilar welding; temper-bead technique, Higuchi's test. 


\section{INTRODUÇÃO}

Devido a grande variedade de componentes e elementos de transição, tais como conectores, válvulas e reguladores de fluxo encontrados em refinarias de petróleo e plantas de geração de energia termoelétrica, comumente existe a necessidade de soldar juntas dissimilares. De acordo com YANG \& KOU [1], a soldagem dissimilar consiste na união de materiais com propriedades físicas e químicas completamente distintas.

Dentre as juntas frequentemente reportadas para as plantas de produção e extração de petróleo, destacam-se as estabelecidas entre os aços inoxidáveis austeníticos e os aços baixa liga (austenítica/ferrítica ), que constantemente estão expostas às condições cíclicas de carregamento e a temperaturas elevadas. Conforme reportado por JOSEPH et al. [2], a diferença entre os coeficientes de expansão térmica dos aços auteníticos e ferríticos promove um acúmulo de tensões durante as variações de temperatura, podendo levar a falha prematura da união. Como alternativa para este problema, metais de adição à base níquel, os quais possuem um coeficiente de expansão térmica intermediário aos aços inoxidáveis austeníticos e aos aços baixa liga, têm sido empregados por resultarem num menor acúmulo de tensões residuais para a junta [2].

Como um dos principais fatores responsáveis pela falha prematura das soldas austeníticas/ferríticas, destaca-se a trinca de tensão por sulfetos (sulfide stress cracking - SSC). Segundo DAI \& LIPPOLD [3], a SSC é essencialmente um tipo de trinca induzida por hidrogênio. Quando introduzido no metal fundido, o hidrogênio difunde para regiões austenitizadas que dispõem de boa solubilidade para o elemento. Com o rápido resfriamento dessa região, a austenita se transforma em martensita e possibilita a nucleação da trinca, uma vez que passa a existir hidrogênio associado a uma microestrutura frágil.

Por conta da microestrutura martensítica, a zona afetada pelo calor (ZAC) dos aços baixa liga é apontada como uma região crítica para a propagação das trincas induzidas por hidrogênio. Dentre os estudos realizados na tentativa de minimizar a fragilização da ZAC, destaca-se o realizado por OLIVEIRA [4], que envolveu a aplicação da técnica de dupla camada. Segundo o autor, esta técnica tem como objetivo principal promover uma adequada sobreposição de ciclos térmicos, de modo que a segunda camada promova o refino e revenimento da ZAC com granulação grosseira da primeira, diminuindo a sensibilidade à fissuração da junta. Assim, para um emprego efetivo da técnica, parâmetros de soldagem adequados devem ser selecionados para cada camada.

Em termos da interface dissimilar, muitos são os artigos científicos que abordam o estudo da zona parcialmente misturada (ZPM) ao longo da zona de ligação, com destaque para Omar [5], DUPONT \& KUSKO [6] e KEJELIN et al. [7]. Segundo estes autores, um dos problemas mais usuais na interface austenítica/ferrítica está associado à formação de uma zona martensítica (Zona M) adjacente à linha de fusão e situada na ZPM que, analogamente a ZAC, também é susceptível as trincas por hidrogênio.

Para DUPONT \& KUSKO [6], a formação da Zona M pode ser minimizada com a substituição de consumíveis de aço inoxidável por ligas de níquel. OMAR [5] complementa afirmando que estas regiões podem ser eliminadas com o uso do consumível correto e de uma combinação adequada de pré-aquecimento. Para KEJELIN et al. [7], a formação dessas regiões tem uma ligação direta com a corrente de soldagem. Quanto menor o nível de corrente menor será a diluição global. A redução de diluição, por sua vez, inibi os movimentos de microsegregação nos transientes iniciais de solidificação e pode suprimir a formação das Zonas $\mathrm{M}$.

Apesar da susceptibilidade as trincas por hidrogênio dos aços inoxidáveis austeníticos, a substituição de ligas à base de níquel por estes aços, sempre que possível, pode ser vista como um importante fator no controle de custos, haja vista que as ligas de níquel são consideravelmente mais onerosas. Neste sentido, o presente trabalho tem como objetivo investigar a viabilidade das técnicas de Higuchi e Higuchi Modificado para a seleção dos parâmetros operacionais para a soldagem controlada pela técnica da dupla camada sobre um aço ARBL, em termos do revenimento da ZAC com granulação grosseira da primeira camada depositada, utilizando uma combinação de metais de adição à base de níquel e de aço inoxidável austenítico.

\section{MATERIAIS E MÉTODOS}

Como metal de base foram utilizadas chapas do aço alta resistência baixa liga (ARBL) ASTM A182 F22 nas dimensões de $100 \mathrm{~mm}$ x $50 \mathrm{~mm}$ x $10 \mathrm{~mm}$. A ZAC do aço ASTM A182 F22 pode possuir em sua microestrutura as presenças de martensita e de bainita, por isso uma das principais precauções com a soldagem deste aço está relacionada às trincas por hidrogênio. A Tabela 1 apresenta a composição química nominal deste aço. 
Tabela 1: Composição química nominal do aço ASTM A182 F22 (\% em peso).

\begin{tabular}{c|c|c|c|c|c|c|c|c}
\hline $\mathbf{C}$ & $\mathbf{P}$ & $\mathbf{M n}$ & $\mathbf{S}$ & $\mathbf{S i}$ & $\mathbf{N i}$ & $\mathbf{C r}$ & $\mathbf{M o}$ & $\mathbf{A l}$ \\
\hline 0,086 & 0,018 & 0,382 & 0,014 & 0,164 & 0,163 & 2,124 & 0,967 & 0,02 \\
\hline
\end{tabular}

Como metais de adição foram utilizados os arames-eletrodos AWS ER NiCrMo-3 e ER 316L, ambos com diâmetro de $1,2 \mathrm{~mm}$. As Tabelas 2 e 3 apresentam a composição química comercial dos respectivos arames.

Tabela 2: Composição química nominal do arame-eletrodo ER NiCrMo-3 (\% em peso).

\begin{tabular}{c|c|c|c|c|c|c|c|c|c|c|c}
\hline $\mathbf{C}$ & $\mathbf{S i}$ & $\mathbf{M n}$ & $\mathbf{C r}$ & $\mathbf{N i}$ & $\mathbf{P}$ & $\mathbf{N b}+\mathbf{T a}$ & $\mathbf{M o}$ & $\mathbf{T i}$ & $\mathbf{F e}$ & $\mathbf{S}$ & Outros \\
\hline $0,1 *$ & $0,5 *$ & $0,5 *$ & 23 & 63,9 & 0,02 & 4,15 & 10 & $0,4 *$ & 5,0 & 0,015 & $0,5^{*}$ \\
\hline
\end{tabular}

Nota:* valores máximos.

Tabela 3: Composição química nominal do arame-eletrodo AWS ER 316L (\% em peso).

\begin{tabular}{c|c|c|c|c|c|c|c|c}
\hline $\mathbf{C}$ & $\mathbf{C r}$ & $\mathbf{N i}$ & $\mathbf{M o}$ & $\mathbf{M n}$ & $\mathbf{P}$ & $\mathbf{S}$ & $\mathbf{F e}$ & Outros \\
\hline $0,03 *$ & 18,0 & 13,0 & 2,0 & 1,5 & $0,03 *$ & $0,03 *$ & Balanceado & $0,50 *$ \\
\hline
\end{tabular}

Nota:* valores máximos.

Uma mistura de $75 \% \mathrm{Ar}+25 \%$ He foi empregada como gás de proteção para o eletrodo ER NiCrMo3 , enquanto que uma mistura de $98 \% \mathrm{Ar}+2 \% \mathrm{O}_{2}$ foi utilizada para o eletrodo ER 316L.

\subsection{Soldagem dos passes isolados}

O sucesso da técnica da dupla camada depende de uma seleção adequada dos parâmetros de soldagem para a $1^{\mathrm{a}}$ e $2^{\mathrm{a}}$ camadas de amanteigamento. Para que isto ocorra, os testes de Higuchi e Higuchi Modificado costumam ser utilizados. A utilização do teste de Higuchi (HIGUCHI et al. [8]) consiste em quantificar o tamanho das zonas dura e macia da ZAC. Esta quantificação é obtida a partir de um perfil de microdureza realizado na ZAC de uma amostra transversal do corpo de prova soldado, que é extraída de passes em simples deposição. O teste de Higuchi Modificado, por sua vez, leva em consideração o tamanho das zonas de grãos grosseiros e grãos finos da ZAC. Assim, conforme sugerido por OLIVEIRA [4], pode-se dizer que, enquanto o teste de Higuchi considera critérios com base na dureza, o teste de Higuchi Modificado considera critérios com base na microestrutura. Deste modo, para aprovação no teste de Higuchi devem ser atendidos os critérios das Equações 1 e 2, enquanto que para aprovação no teste de Higuchi Modificado devem ser atendidos os critérios das Equações 3 e 4 . Após a quantificação das regiões de interesse, resultam os diagramas de decisão com base na metodologia proposta por MIRANDA [9]. Estes diagramas objetivam selecionar as condições de soldagem para a $1^{\mathrm{a}}$ e $2^{\mathrm{a}}$ camadas de amanteigamento, considerando os critérios de Higuchi e Higuchi Modificado. A Figura 1 apresenta um esquema, similar ao desenvolvido por AGUIAR [10], com as regiões de interesse utilizadas para atender aos critérios de Higuchi e Higuchi Modificado.

$P Z M 2-P Z D 1>0$

Nota: $\mathrm{PZM}_{2}=$ profundidade da zona macia da segunda camada $\mathrm{PZD}_{1}=$ profundidade da zona dura da primeira camada

$R 1+P 1-P Z D 2>0$

Nota: $\mathrm{PZD}_{2}=$ profundidade da zona dura da segunda camada

$\mathrm{R}_{1}=$ reforço da primeira camada

$\mathrm{P}_{1=\text { penetração da primeira camada }}$ 
$P Z A C G F 2-P Z A C G G 1>0$

Nota: PZACGF $\mathrm{F}_{2}=$ profundidade da ZAC com granulação fina da segunda camada $\mathrm{PZACGG}_{1}=$ profundidade da ZAC com granulação grosseira da primeira camada

\section{$Z F 1-P Z A C G G 2>0$}

Nota: $\mathrm{PZACGG}_{2}=$ profundidade da ZAC com granulação grosseira da segunda camada $\mathrm{ZF}_{1}=$ zona fundida da primeira camada
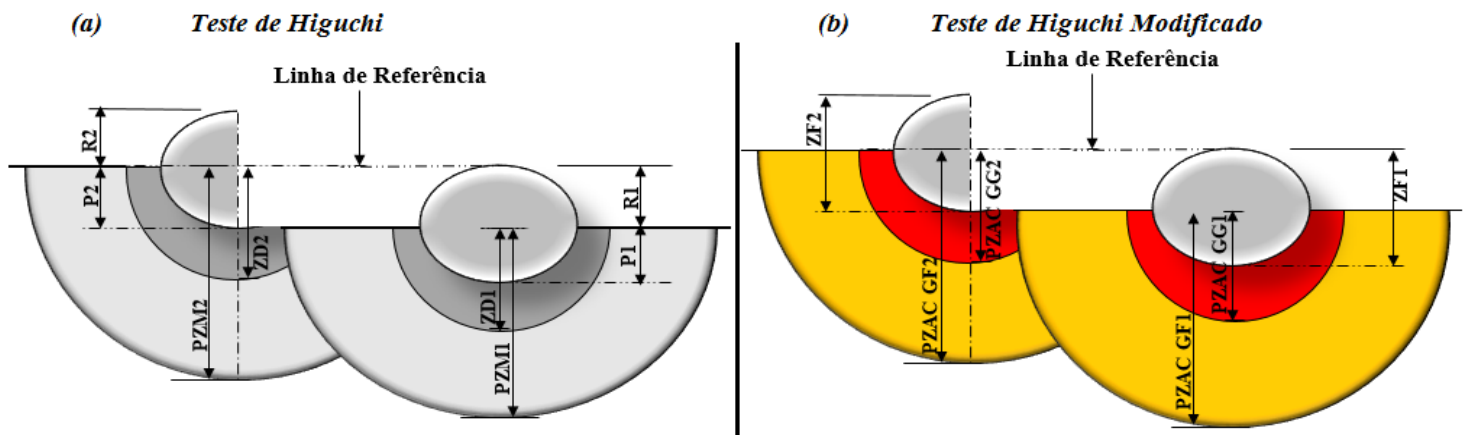

Figura 1: Ilustração das regiões consideradas pelos critérios dos testes de (a) Higuchi e (b) Higuchi Modificado.

Durante a deposição dos passes isolados foi utilizada uma fonte eletrônica e um carro de deslocamento automatizado. Para o eletrodo ER 316L, empregou-se o processo GMAW com corrente convencional. Visando a obtenção de uma menor corrente média em relação à corrente convencional para uma mesma taxa de deposição, o eletrodo ER NiCrMo-3 foi depositado pelo processo GMAW com corrente pulsada. Todos os passes foram depositados na posição plana, com sentido empurrando (ângulo de ataque de $75^{\circ}$ ), distância bico-de-contato peça (DBCP) de $15 \mathrm{~mm}$ e com vazão de gás de 15 1/min. Além disso, por meio de um aquecimento à chama (oxi-acetilênica) e de um pirômetro infravermelho, uma faixa de temperatura de préaquecimento foi mantida entre $250{ }^{\circ} \mathrm{C}$ e $270{ }^{\circ} \mathrm{C}$. A Tabela 4 apresenta os parâmetros de soldagem, onde a nomenclatura $\mathrm{Ni}$ é adotada para as soldas com o eletrodo níquel (ER NiCrMo-3) e a nomenclatura Inox é adotada para as soldas com o eletrodo de aço inoxidável (ER 316L).

Tabela 4: Parâmetros de soldagem adotados no trabalho.

\begin{tabular}{c|c|c|c|c|c|c|c|c|c}
\hline Exp. & $\begin{array}{c}\mathbf{V}_{\mathbf{s}} \\
(\mathbf{c m} / \mathbf{m i n})\end{array}$ & $\mathbf{V}_{\mathbf{a}} \mathbf{( m / \mathbf { m i n } )}$ & $\mathbf{I p}(\mathbf{A})$ & $\mathbf{t p}(\mathbf{s})$ & $\mathbf{I b}(\mathbf{A})$ & $\mathbf{t b}(\mathbf{s})$ & $\mathbf{I m} \mathbf{( A )}$ & $\mathbf{U m} \mathbf{( V )}$ & $\begin{array}{c}\text { Energia } \\
(\mathbf{J} / \mathbf{m m})\end{array}$ \\
\hline Ni1 & 30 & 5 & 350 & 2 & 160 & 20 & 164 & 27,7 & 982 \\
\hline Ni2 & 30 & 5 & 350 & 2 & 135 & 20 & 151 & 24,8 & 766 \\
\hline Ni3 & 30 & 6 & 300 & 3 & 120 & 6 & 177 & 26,6 & 957 \\
\hline Ni4 & 40 & 6 & 300 & 3 & 120 & 6 & 176 & 26,3 & 710 \\
\hline Ni5 & 30 & 4,3 & 280 & 2,4 & 90 & 7 & 136 & 26,0 & 720 \\
\hline Ni6 & 40 & 4,3 & 280 & 2,4 & 90 & 7 & 134 & 27,7 & 575 \\
\hline Inox1 & 30 & 6 & - & - & - & - & 210 & 27 & 1134 \\
\hline Inox2 & 40 & 6 & - & - & - & - & 210 & 27 & 850 \\
\hline Inox3 & 50 & 6 & - & - & - & - & 210 & 27 & 680 \\
\hline Inox4 & 30 & 8 & - & - & - & - & 280 & 31 & 1736 \\
\hline Inox5 & 40 & 8 & - & - & - & - & 280 & 31 & 1336 \\
\hline Inox6 & 50 & 8 & - & - & - & - & 280 & 31 & 1041 \\
\hline
\end{tabular}

Nota: $\mathrm{V}_{\mathrm{s}}$ representa a velocidade de soldagem; $\mathrm{V}_{\mathrm{a}}$ representa a velocidade de alimentação, Ip representa a corrente de pico; tp representa o tempo de pico; Ib representa a corrente de base; tb representa o tempo de base; Im representa a corrente média; Um representa a tensão média. 
Os passes em simples deposição foram seccionados em três amostras transversais (amostras A, B e C) que, em seguida, foram submetidas à preparação metalográfica para medição das características geométricas (reforço, penetração, diluição), levantamento dos perfis de microdureza ao longo da ZAC (determinação das zonas duras (ZD) e macias (ZM)) e quantificação da extensão da ZAC de grãos grosseiros (ZACGG) e da ZAC de grãos finos (ZACGF). A Figura 2 apresenta o esquema de corte das amostras transversais. A Figura 3 apresenta o esquema de medição geométrica.

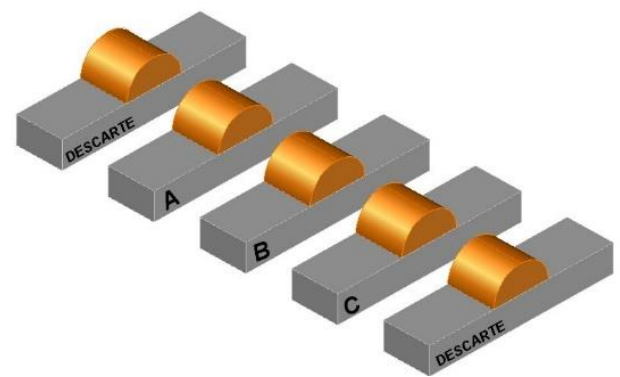

Figura 2: Esquema de corte das amostras transversais em cada cordão.

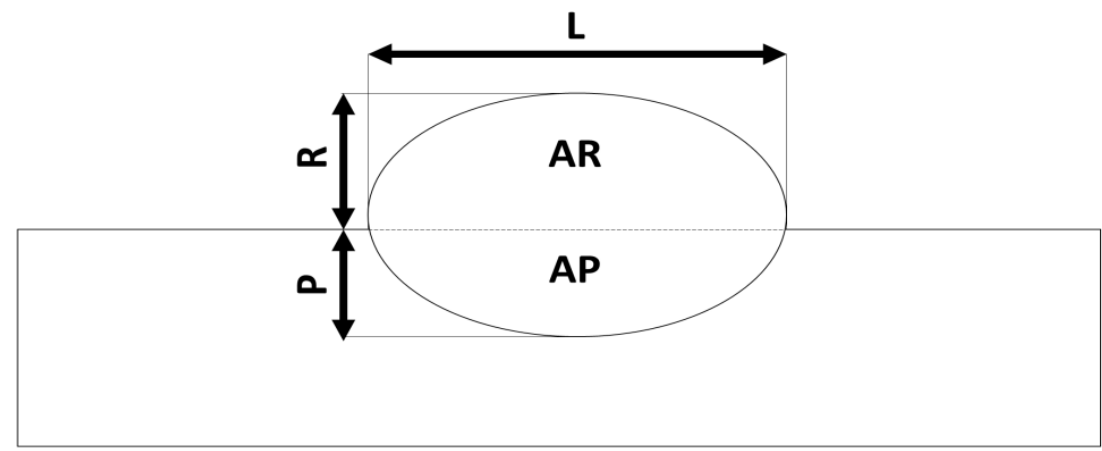

Figura 3: Esquema de medição geométrica (R representa o reforço, $\mathrm{P}$ representa a penetração, L representa a largura do cordão, AR representa a área do reforço e AP representa a área da penetração).

Para quantificação da extensão das zonas dura e macia, o ensaio de microdureza foi realizado na amostra transversal B. Um carregamento de $0,1 \mathrm{HV}$ e um tempo de $15 \mathrm{~s}$ foram empregados como parâmetros do ensaio. Além disso, um espaçamento entre indentações de $0,1 \mathrm{~mm}$ foi utilizado, de modo atender a norma ASTM E384 [11]. A quantificação das zonas dura e macia requer o estabelecimento de valores de dureza que limitam as duas regiões. Desta forma, o limite inferior da zona dura (LZD) e o limite inferior da zona macia (LZM) foram fixados em $310 \mathrm{HV}$ e em $220 \mathrm{HV}$, respectivamente, conforme sugeridos por Oliveira [4]. Por fim, para a quantificação das extensões das zonas de grãos grosseiros e grãos finos dentro da ZAC, analisaram-se as micrografias e, com o auxílio da linha de indentações deixada, mediram-se as extensões da ZACGG e da ZACGF. A Figura 4 ilustra um esquema da região analisada pelo ensaio de microdureza.

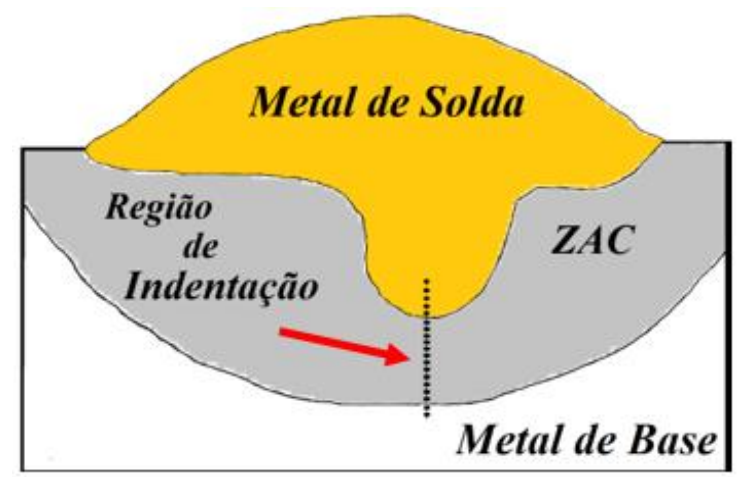

Figura 4: Esquema do ensaio de microdureza nas amostras em simples deposição 


\subsection{Soldagem de dupla camada com deposição sobre chapas}

Vale ressaltar que a utilização do eletrodo de níquel foi restringida para a primeira camada, ao passo que o uso do eletrodo de aço inoxidável foi restringido para a segunda. Estas escolhas são baseadas nos resultados encontrados por DUPONT \& KUSKO [3], que indicaram a existência de regiões martensíticas maiores na interface dissimilar para uma liga de aço inox austenítico em relação à liga ER NiCrMo-3. Durante a confecção dos revestimentos, uma sobreposição de $50 \%$ foi utilizada. Para a primeira camada foram realizados um total de cinco passes, enquanto que para a segunda camada realizaram-se quatro passes. De forma a replicar as condições da etapa anterior, uma faixa de temperatura de pré-aquecimento foi mantida entre $250{ }^{\circ} \mathrm{C}$ e 270 ${ }^{\circ} \mathrm{C}$. A Figura 5 indica o esquema de sobreposição adotado.
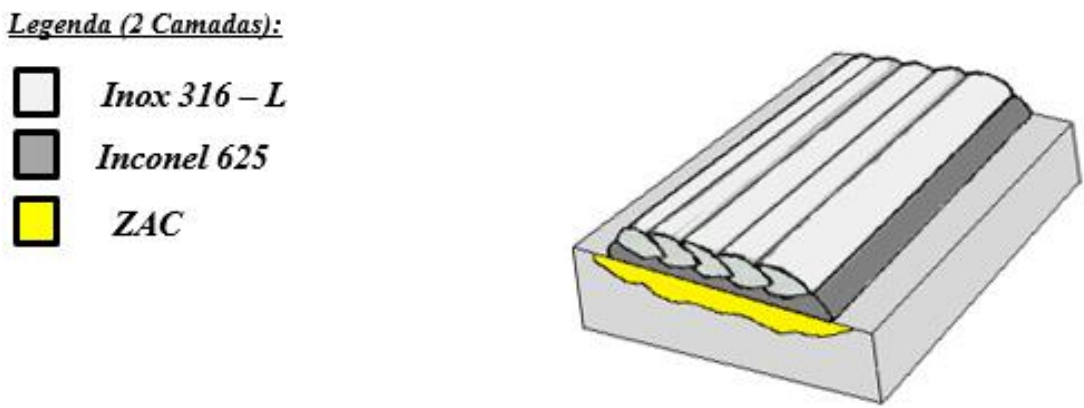

Figura 5: Esquema da sobreposição das camadas de revestimento.

Após a soldagem de revestimento, duas amostras transversais foram seccionadas. A primeira serviu para analisar a eficiência da técnica da dupla camada e a segunda para avaliar a eficiência de um tratamento térmico de alívio de tensões (TTAT). A Tabela 5 apresenta as condições do TTAT.

Tabela 5: Parâmetros de TTAT utilizados na amostra revestida.

\begin{tabular}{c|c|c}
\hline Temperatura $\left({ }^{\circ} \mathbf{C}\right)$ & Tempo $(\mathbf{m i n})$ & Tipo de resfriamento \\
\hline 650 & 120 & Ar calmo \\
\hline
\end{tabular}

Após a etapa metalográfica, as amostras foram submetidas ao ensaio de microdureza. Para isso, uma linha de indentações percorreu a ZAC a partir do centro do terceiro cordão da primeira camada, utilizando uma carga de $0,1 \mathrm{HV}$, um tempo $15 \mathrm{~s}$ e uma distância entre as indentações de $0,1 \mathrm{~mm}$, respeitando a norma ASTM E384 [11]. A Figura 6 apresenta o esquema do ensaio de microdureza nas amostras revestidas.

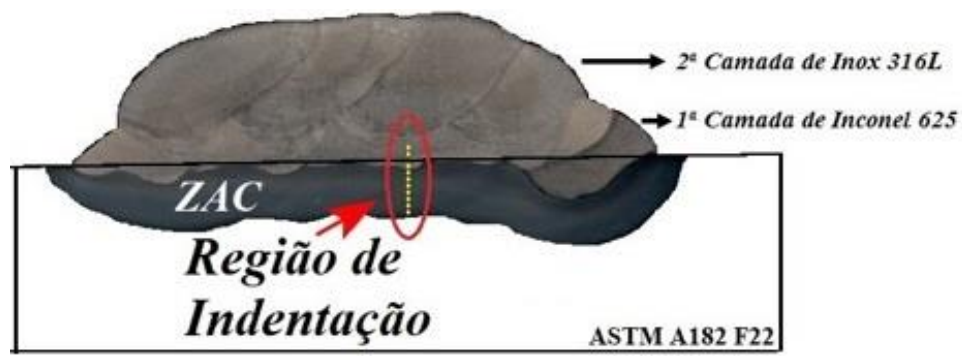

Figura 6: Esquema de realização do ensaio de microdureza nas amostras revestidas.

\section{RESULTADOS E DISCUSSÃO}

\subsection{Soldagem dos passes isolados}

As Figuras 7 e 8 indicam as macrografias das amostras transversais B para os eletrodos de níquel e de aço inoxidável, respectivamente. Pela análise destas figuras, verifica-se que os cordões não apresentaram nenhum tipo de defeito. Percebe-se também menores penetrações para as soldas com a liga de níquel devido a utilização de baixos níveis de energia e da pulsação de corrente, as quais tendem a diminuir a penetração e, consequentemente, a diluição. Outro fator importante está relacionado à penetração do tipo cálice, observada nas amostras depositadas com o arame ER316L, que advém da mistura gasosa empregada para proteção. De acordo com Scotti \& Ponomarev [12], este tipo de penetração ocorre quando a contribuição da quantidade de 
movimento efetiva é expressiva na formação do cordão, caso típico de misturas gasosas com altos teores de Ar e baixos teores de $\mathrm{O}_{2}$ e/ou $\mathrm{CO}_{2}$.

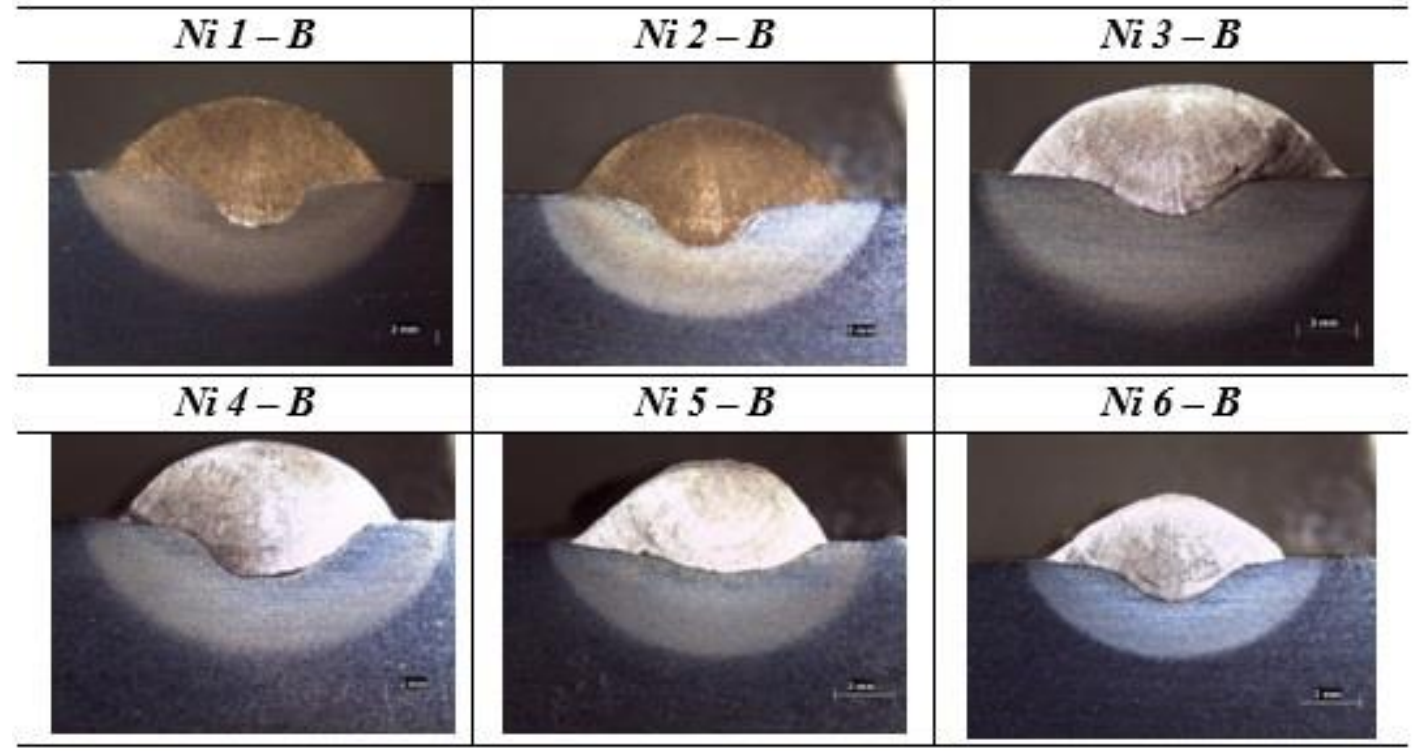

Figura 7: Macrografias das seções transversais B dos cordões depositados com o arame ER NiCrMo-3.

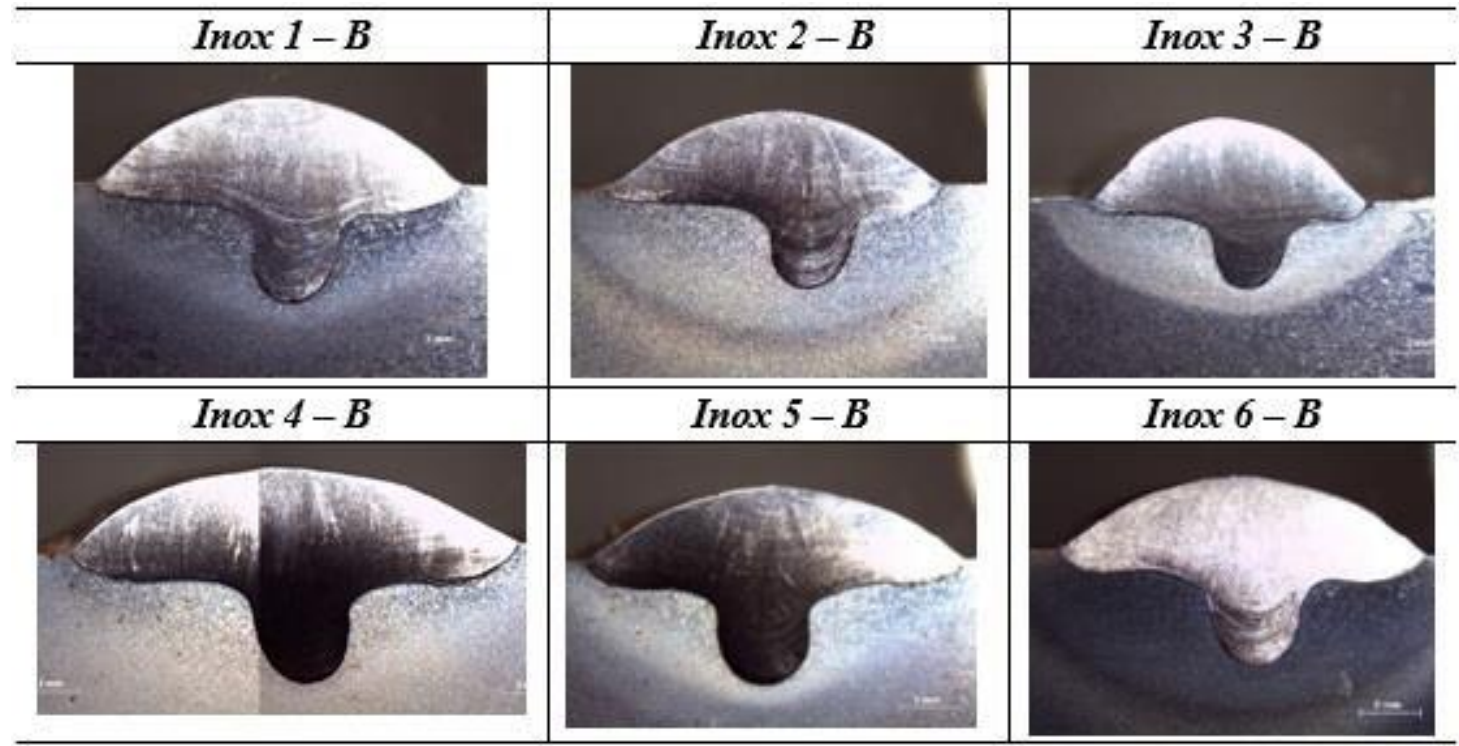

Figura 8: Macrografias das seções transversais B dos cordões depositados com o arame ER 316L.

A Tabela 6 apresenta os valores médios de largura, reforço e penetração determinados para cada condição de soldagem. Em termos dos resultados de penetração, verificam-se maiores valores para o eletrodo ER 316L devido as maiores energias de soldagem, o gás de proteção e o modo de corrente utilizados em relação ao eletrodo de níquel.

Tabela 6: Valores médios de penetração, reforço e largura para cada passe isolado.

\begin{tabular}{c|c|c|c}
\hline Exp. & Largura $(\mathbf{m m})$ & Reforço $(\mathbf{m m})$ & Penetração $\mathbf{( m m})$ \\
\hline Ni 1 & 10,56 & 2,62 & 2,17 \\
\hline Ni 2 & 9,61 & 2,78 & 1,47 \\
\hline Ni 3 & 11,34 & 3,21 & 1,74 \\
\hline Ni 4 & 9,48 & 2,69 & 2,10 \\
\hline Ni 5 & 8,73 & 2,70 & 1,16 \\
\hline
\end{tabular}




\begin{tabular}{c|c|c|c}
\hline Ni 6 & 7,82 & 2,18 & 1,50 \\
\hline Inox 1 & 12,39 & 2,86 & 3,76 \\
\hline Inox 2 & 10,65 & 2,54 & 3,33 \\
\hline Inox 3 & 8,73 & 2,43 & 2,60 \\
\hline Inox 4 & 16,86 & 2,62 & 4,55 \\
\hline Inox 5 & 13,09 & 2,63 & 4,31 \\
\hline Inox 6 & 11,94 & 2,63 & 3,84 \\
\hline
\end{tabular}

A título de exemplo, as Figuras 9 e 10 apresentam dois perfis de microdureza obtidos para os arames a base de níquel e de aço inoxidável, respectivamente. Nessas figuras, MS representa o metal de solda, ZD representa a zona dura, ZM representa a zona macia, MB representa o metal de base, LZD representa o limite inferior da zona dura e LZM representa o limite inferior da zona mole.

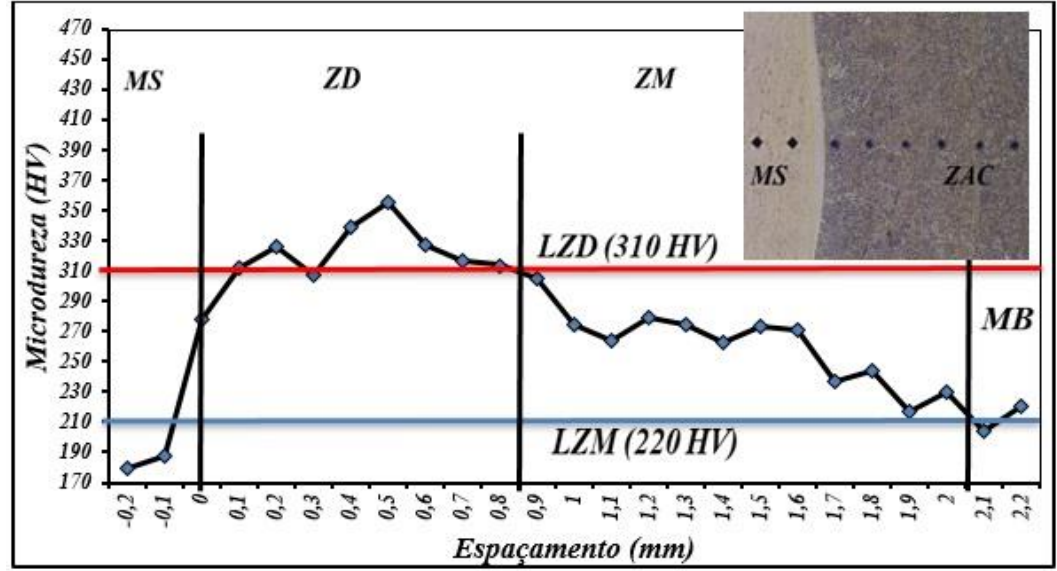

Figura 9: Perfil de microdureza para amostra Ni 4 (710 J/mm).

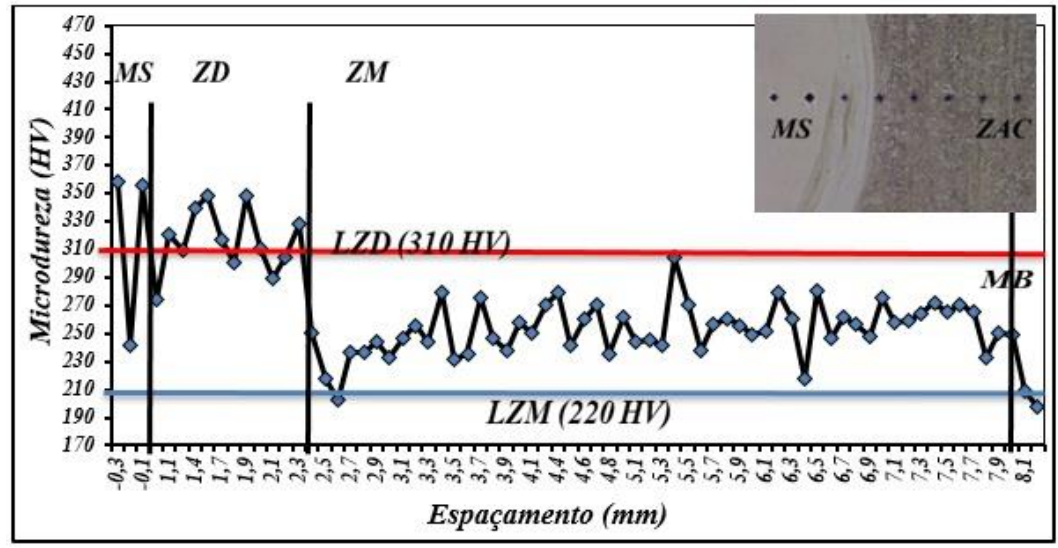

Figura 10: Perfil de microdureza para amostra Inox $2(850 \mathrm{~J} / \mathrm{mm})$.

Ao avaliar os resultados de microdureza das Figuras 9 e 10 na região do metal de solda (MS) próximo à linha de fusão, verifica-se que a condição com o eletrodo à base de níquel apresenta valores inferiores (menores que 190 HV) em relação à condição com o eletrodo de aço inoxidável, que apresentou microdurezas de ordem superior a $350 \mathrm{HV}$. Este resultado sugere a formação de martensita na interface dissimilar da condição depositada com o eletrodo de aço inoxidável. Para confirmar a presença de regiões martensíticas para a condição Inox 2, uma micro análise química via EDS foi realizada na interface da amostra de forma a permitir a predição da microestrutura com o auxílio do diagrama de Schaeffler. A Figura 11 apresenta as micrografias eletrônicas de varredura realizadas sobre a interface da condição Inox 2 e a região analisada via EDS. 


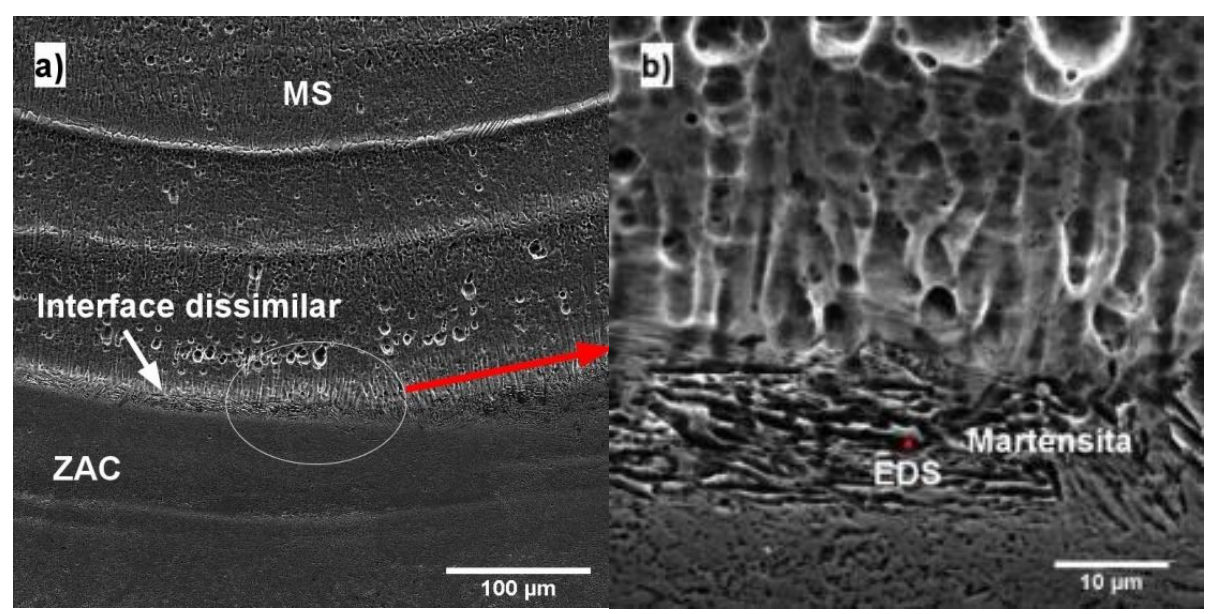

Figura 11: a) Microscopia eletrônica de varredura da interface dissimilar da condição Inox 2. b) região de análise química pontual via EDS.

A Tabela 7 apresenta os resultados de composição química obtidos via EDS e os valores de níquel e cromo equivalentes calculados para a predição da microestrutura no diagrama. A Figura 12 apresenta o ponto de interseção encontrado no diagrama de Schaeffler a partir dos valores de $\mathrm{Ni}_{\mathrm{eq}}$ e $\mathrm{Cr}_{\mathrm{eq}}$ determinados.

Tabela 7: Composição química quantificada via EDS.

\begin{tabular}{|c|c|c|c|c|c|c|}
\hline \multicolumn{5}{|c|}{ \% em peso } & \multirow[b]{2}{*}{$\mathrm{Cr}_{\mathrm{eq}} *$} & \multirow[b]{2}{*}{$\mathrm{Ni}_{\mathbf{e q}}$ * } \\
\hline $\mathbf{N i}$ & Mn & $\mathrm{Cr}$ & Mo & $\mathbf{S i}$ & & \\
\hline 3,48 & 0,75 & 9,1 & 1,3 & 0,21 & 10,715 & 4,82556 \\
\hline
\end{tabular}

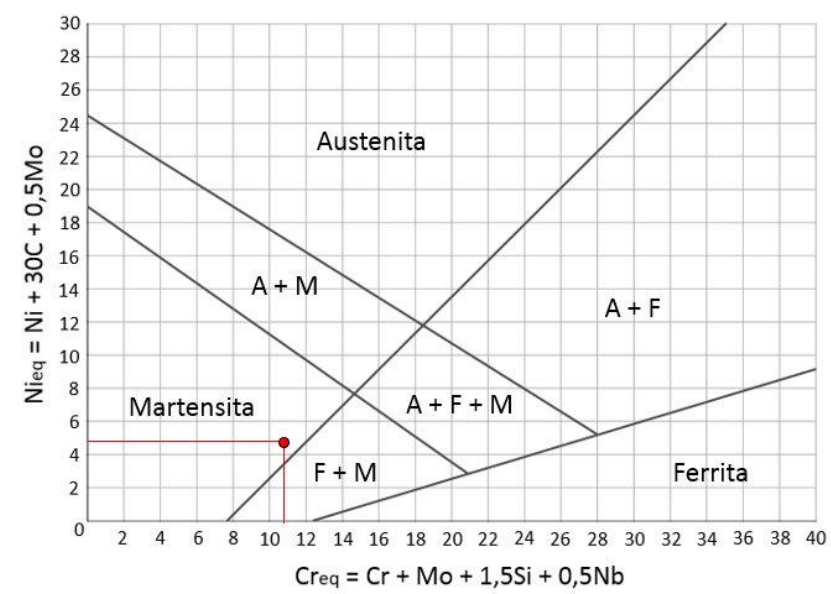

Figura 12: Ponto analisado via EDS inserido no diagrama constitucional de Schaeffler.

A análise do diagrama da Figura 12 indica a existência da região martensítica para a condição Inox 2. Do mesmo modo, os próprios resultados de microdureza do metal de solda adjacente à linha de fusão e a morfologia da microestrutura na Figura 11(b) corroboram a presença deste microconstituinte.

Além da existência de martensita devido o gradiente constitucional formado na interface, este microconstituinte também foi identificado em grande parte dos cordões depositados pelo eletrodo de aço inoxidável devido à formação de ilhas e penínsulas frequentes, estabelecidas ao longo da interface. Para o eletrodo ER NiCrMo-3 também se verificaram algumas destas macrosegregações, porém em menor frequência quando comparado ao eletrodo ER 316L. Acredita-se que os mesmos fatores que levaram a uma maior penetração para os cordões com o eletrodo ER 316L, isto é, maiores energias de soldagem, utilização do gás argônio e o uso do modo de corrente convencional, podem ter intensificado a ação de forças convectivas dentro da poça de fusão, aumentando à possibilidade de surgimento de macrosegregações. A Figura 13 ilustra algumas macrosegregações observadas na interface do metal de solda com o metal de base para as condições Inox 3 e $\mathrm{Ni}$ 4. 


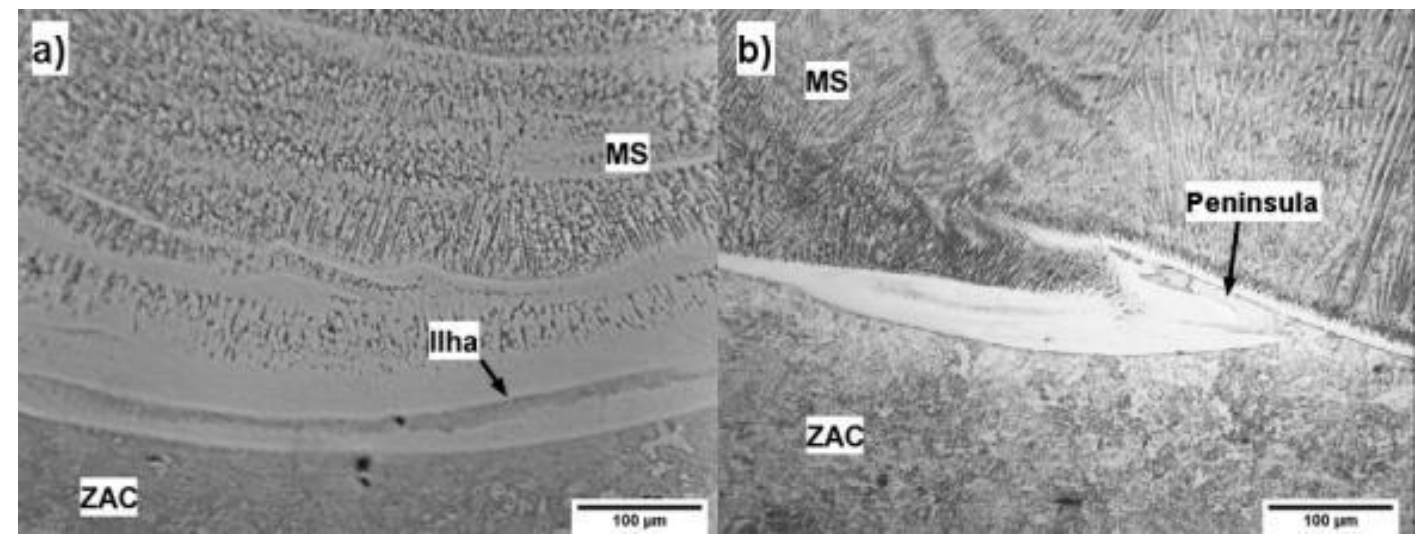

Figura 13: Interface da zona de ligação: a) Inox 3; b) Ni 4.

A Tabela 8 apresenta as extensões quantificadas da zona dura (ZD) e da zona macia (ZM) a partir dos ensaios de microdureza, e também as extensões quantificadas para a ZAC de grãos grosseiros (ZACGG) e para a ZAC de grãos finos (ZACGF). A partir dos resultados da Tabela 8, chegou-se aos diagramas de Higuchi (Figura 14) e de Higuchi Modificado (Figura 15).

Tabela 8: Extensões das zonas duras (ZD) e macias (ZM) na ZAC.

\begin{tabular}{c|c|c|c|c}
\hline & ZD $(\mathbf{m m})$ & $\mathbf{Z M}(\mathbf{m m})$ & GG $(\mathbf{m m})$ & GF $(\mathbf{m m})$ \\
\hline Ni 1 & 0,90 & 1,30 & 0,8 & 1,40 \\
\hline Ni 2 & 0,40 & 1,50 & 0,70 & 1,20 \\
\hline Ni 3 & 2,70 & 1,00 & 2,70 & 1,00 \\
\hline Ni 4 & 0,80 & 1,00 & 0,90 & 0,90 \\
\hline Ni 5 & 1,20 & 1,50 & 1,00 & 1,70 \\
\hline Ni 6 & 1,00 & 0,80 & 0,90 & 0,90 \\
\hline Inox 1 & 0,40 & 0,60 & 0,40 & 0,60 \\
\hline Inox 2 & 1,30 & 5,70 & 1,20 & 5,80 \\
\hline Inox 3 & 0,40 & 0,40 & 0,40 & 0,40 \\
\hline Inox 4 & 2,10 & 2,80 & 2,20 & 2,70 \\
\hline Inox 5 & 0,50 & 0,60 & 0,50 & 0,60 \\
\hline Inox 6 & 1,10 & 5,30 & 1,20 & 5,20 \\
\hline
\end{tabular}

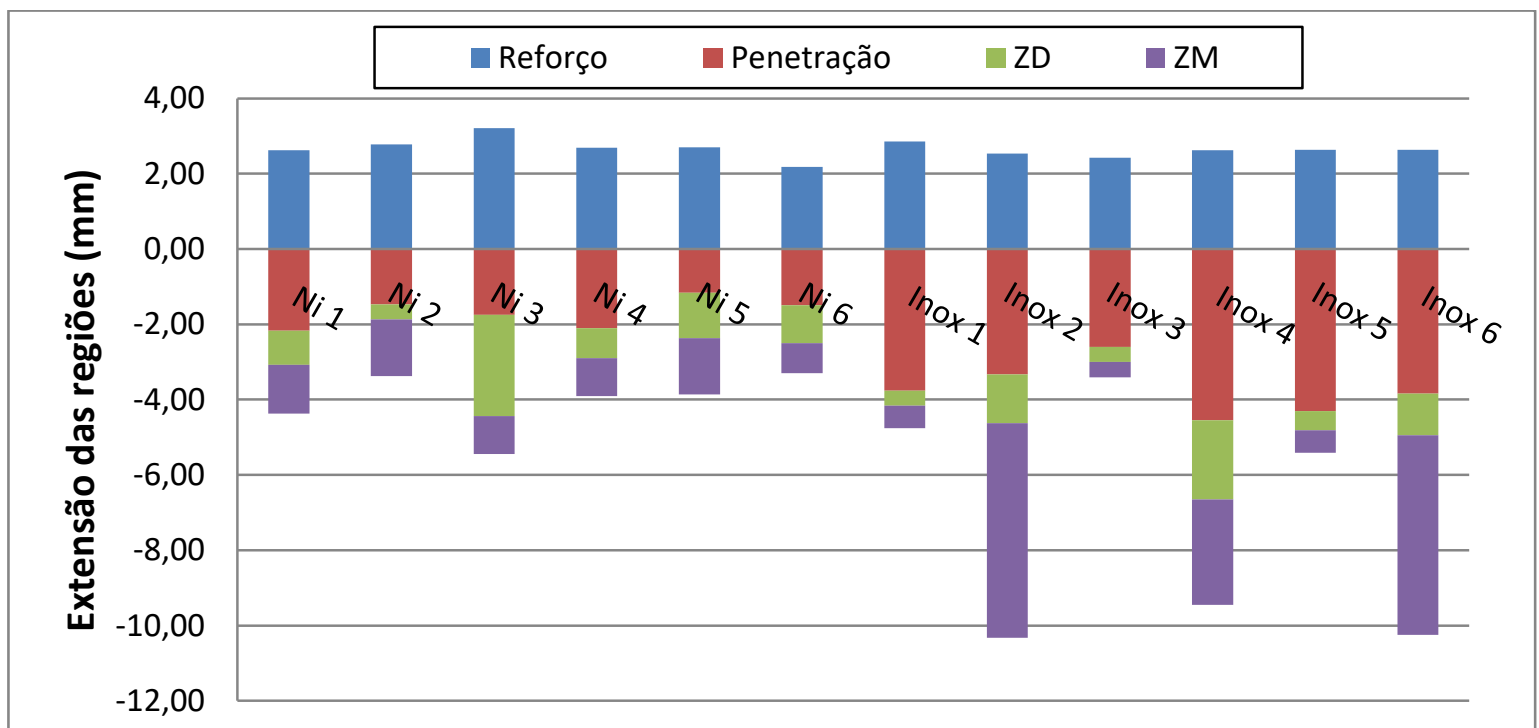

Figura 14: Diagrama de Higuchi. 


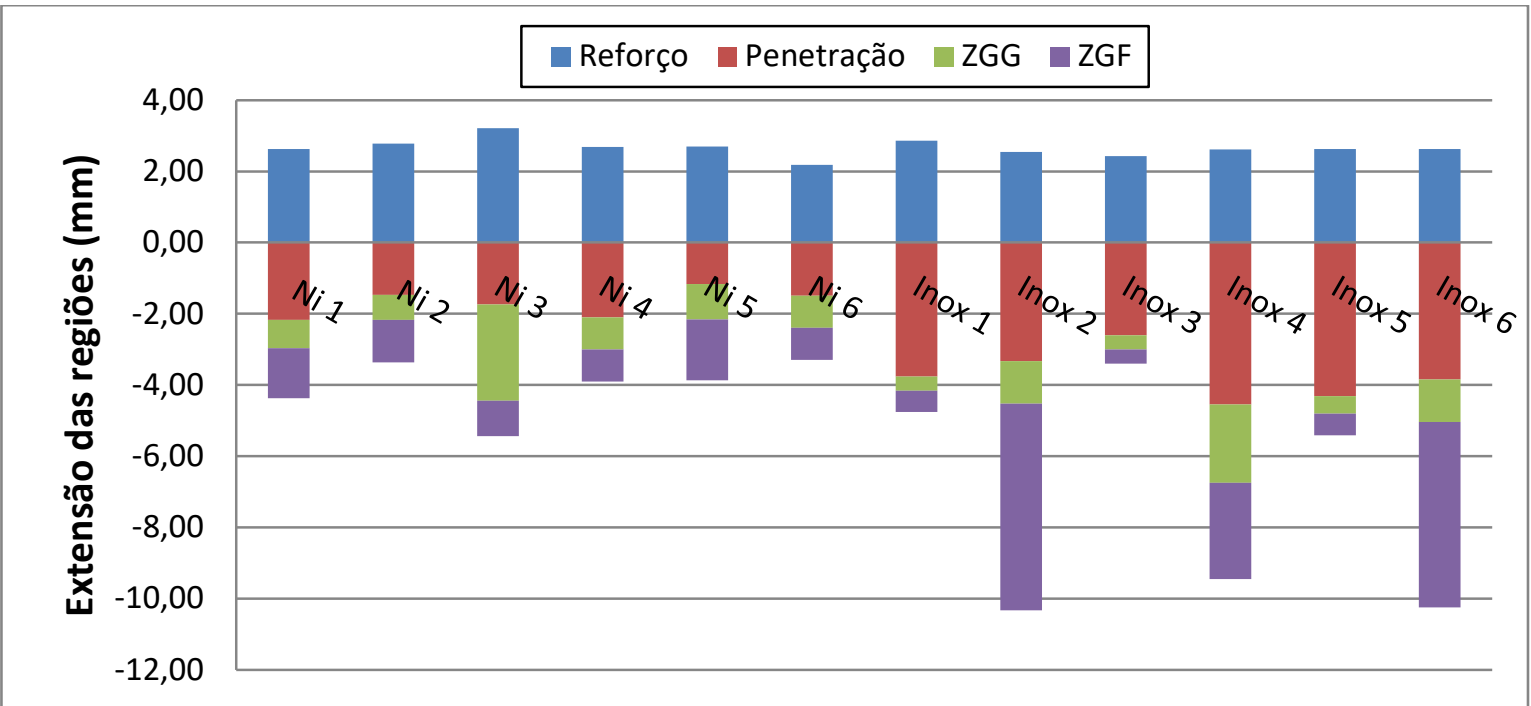

Figura 15: Diagrama de Higuchi Modificado.

Em ambos os diagramas, observam-se variações na extensão das regiões avaliadas para as diferentes condições, devido aos diferentes níveis de energia de soldagem selecionados durante o planejamento experimental. Conforme comentado, é de interesse que o arame ER 316L seja empregado na segunda camada (redução de custo) de revestimento e, por isso, condições de maior energia foram selecionadas para esta liga. Do contrário, o ciclo térmico imposto pela segunda camada não seria capaz de vencer a barreira física do metal de solda e, tão pouco, reveniria a zona dura da ZAC, imposta pela primeira camada de revestimento.

Obtidos os diagramas de Higuchi e Higuchi Modificado, partiu-se para elaboração dos diagramas de decisão que objetivam avaliar a aprovação dos parâmetros para a $2^{\mathrm{a}}$ camada de revestimento, de acordo com os diferentes critérios adotados pelos testes de Higuchi e Higuchi Modificado. A Figura 16 apresenta o diagrama de decisão elaborado considerando a condição Ni 4 na primeira camada de amanteigamento.

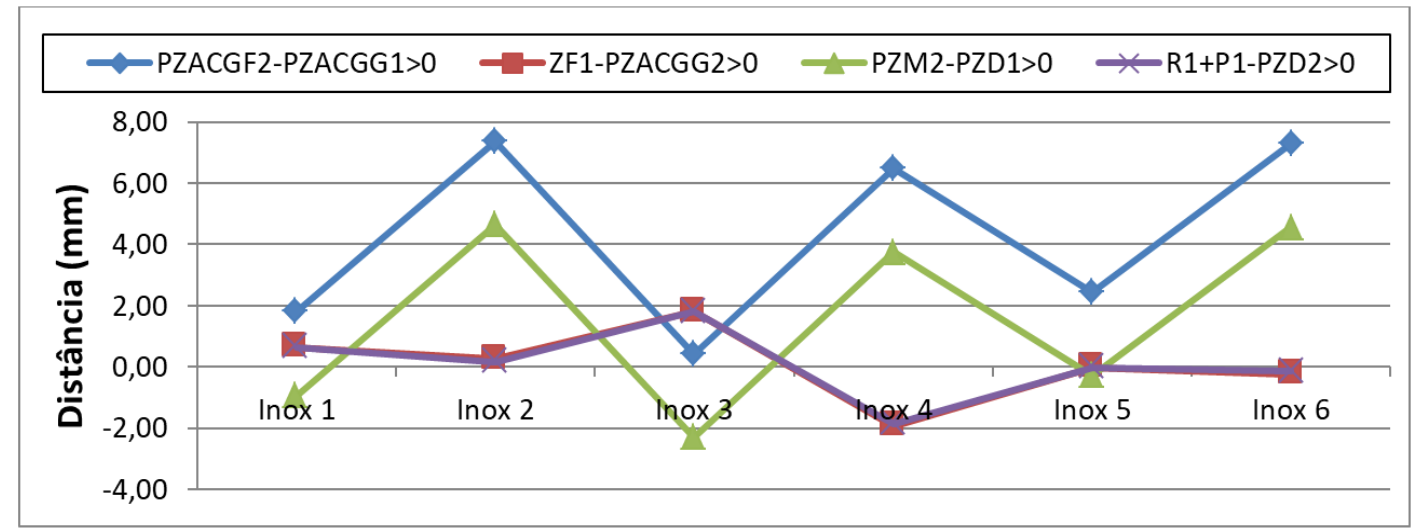

Figura 16: Diagrama de decisão para a condição Ni 4.

Nos diagramas de decisão, as condições que se encontram abaixo da linha de referência não devem ser utilizadas devido o risco da extensão da zona dura da $1^{a}$ camada. Assim, analisando o diagrama de decisão da Figura 16, verifica-se que somente a condição Inox 2 se mostrou satisfatória para sobrepor a primeira camada com a condição Ni 4. Apesar disso, as condições Inox 5 e 6 ficaram próximas da aprovação para a segunda camada.

\subsection{Soldagem de dupla camada com deposição sobre chapas}

A Tabela 9 apresenta as duas condições selecionadas pelos diagramas de decisão para a soldagem da dupla camada. A Figura 17 ilustra o aspecto superficial e a seção transversal do revestimento. 
Tabela 9: Condições da soldagem de revestimento.

\begin{tabular}{c|c|c|c}
\hline Revestimento & Condição & Dupla camada & Energia $(\mathbf{J} / \mathbf{m m})$ \\
\hline \multirow{2}{*}{ Inox $2 / \mathrm{Ni} 4$} & $\mathrm{Ni} 4$ & $1^{\mathrm{a}}$ camada & 710,10 \\
\cline { 2 - 4 } & Inox 2 & $2^{\mathrm{a}}$ camada & 850,50 \\
\hline
\end{tabular}
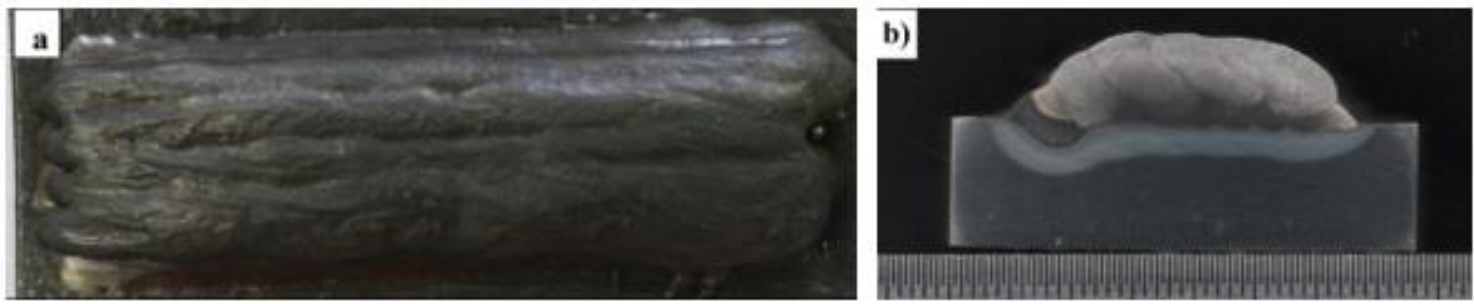

Figura 17: (a) Aspecto superficial e (b) macrografia do revestimento.

Analisando o aspecto superficial e a macrografia, não se observam descontinuidades capazes de comprometer a qualidade do revestimento. Com a finalidade de avaliar o nível de revenimento adquirido pela técnica da dupla camada, a Figura 18 apresenta os perfis de microdureza levantados para a condição de passe isolado $\mathrm{Ni} 4$ e para o revestimento Inox $2 / \mathrm{Ni} 4$.

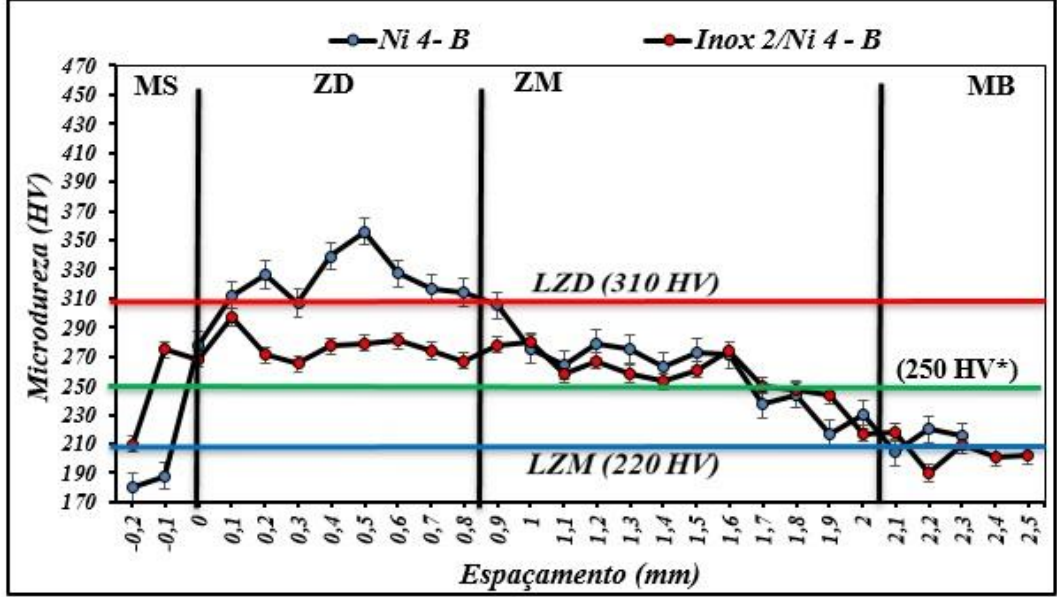

Figura 18: Perfil de microdureza para o passe isolado Ni 4 e para o revestimento Inox 2/Ni 4.

A Figura 18 mostra uma redução de microdureza considerável para o revestimento Inox 2/ Ni 4 devido a aplicação dos testes de Higuchi e Higuchi Modificado durante a seleção das condições para a técnica da dupla camada. Apesar do revenimento alcançado, as microdurezas na ZAC do revestimento não se mantiveram abaixo do nível máximo de microdureza $(250 \mathrm{HV})$ recomendado pela norma NACE MR0175 [8]. Assim, para atender aos requisitos estabelecidos, uma das duas amostras de revestimento foi submetida a um TTAT. A Figura 19 apresenta os perfis de microdureza para as amostras revestidas com (Inox 2/Ni 4 - TT) e sem TTAT (Inox 2/Ni 4). 


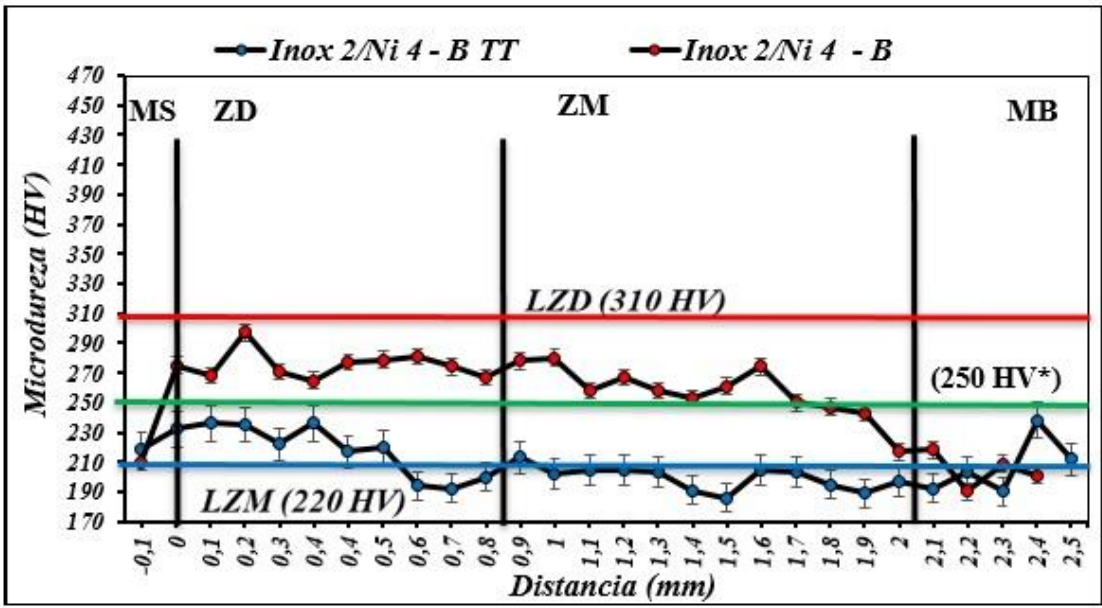

Figura 19: Perfis de microdureza para as amostras revestidas com (Inox 2/Ni 4 - TT) e sem TTAT (Inox 2/Ni 4).

Analisando os perfis de microdureza da Figura 19, constata-se uma redução significativa para a amostra tratada termicamente, inclusive, para os patamares recomendados pela NACE MR0175. Desta forma, pode-se dizer que apesar de existir uma redução de microdureza por meio da utilização dos testes de Higuchi e Higuchi Modificado para a execução da técnica da dupla camada, o nível de revenimento alcançado ainda é insuficiente ao ponto de eliminar completamente o uso de TTAT. Contudo, ao invés de utilizar somente o eletrodo de níquel, como de costume, a combinação dos dois eletrodos pode ser considerada vantajosa já que pode resultar em uma redução de custos relacionada aos materiais de consumo, uma vez que um consumível de níquel pode custar muito mais do que um de aço inoxidável.

\section{CONCLUSÃO}

Nas condições estabelecidas neste trabalho, o uso da técnica da dupla camada não atendeu ao limite de microdureza estabelecido pela norma NACE MR0175, havendo a necessidade de um TTAT complementar.

\section{AGRADECIMENTOS}

Os autores agradecem as agências de pesquisa e desenvolvimento (FINEP - $\mathrm{n}^{\circ}$ contrato:01.10.0723.04, CAPES, CNPq, PETROBRAS/CENPES, REMULT/Núcleo de União e Revestimento de Materiais) que forneceram o apoio financeiro para a realização deste trabalho.

\section{BIBLIOGRAFIA}

[1] YANG, Y.K, KOU. Mechanisms of macrosegregation formation near fusion boundary in welds made with dissimilar filler metals. ASM International, 2007.

[2] JOSEPH, A., RAI, K., JAYAKUMAR, T., et al. Evaluation of residual stresses in dissimilar weld joints. International Journal of Pressure Vessels and Piping v. 82 pp. 700 -705. 2005.

[3] DAI, T., LIPPOLD, J.C.Tempering Behavior of the Fusion Boundary Region of an F22/625 Weld Overlay. Welding Journal 96, pp. 467s -480s, 2017.

[4] OLIVEIRA, G.L.G., Soldagem dissimilar dos aços AISI 8630M e ASTM A182 F22 para aplicações subaquáticas, Tese de Doutorado, UFC, Fortaleza, CE, Brasil, 2013.

[5] OMAR, A.A. Effects of welding parameters on hard zone formation at dissimilar welds. Welding Journal. v. 87, n. 2, pp. 86s-93s, 1998.

[6] DUPONT, J.N., KUSKO, C.S. Technical note: Martensite formation in austenitic/ferritic dissimilar alloy welds. Welding Journal. v. 86, n. 2, pp. 51-54, 2007.

[7] KEJELIN, N.Z., BUSCHINELLI, A.J.A., POPE, A.M. Influence of welding parameters on the formation of partially diluted zones of dissimilar metal welds. Soldagem e Inspeção 12 (3), pp.195 - 203. 2007.

[8] HIGUCHI, M., SAKAMOTO, H., TANIOKA, S. A study on weld repair through half bead method. IHI Engineering Review, v. 13, n.2, pp. 14-19, 1980.

[9] MIRANDA, H.C. Aplicação da dupla camada na soldagem de aços ASTM A516 Gr. 70. Tese de Doutorado, UFC, Fortaleza, CE, Brasil, 2009.

[10] AGUIAR, W.M. Soldagem do aço ABNT 4140 sem Tratamento Térmico posterior. Dissertação de Msc., UFC, Fortaleza, CE, Brasil, 2001.

[11] ASTM E384 - 11. Standard Test Method for Knoop and Vickers Hardness of Materials. ASTM International. 2011. 
[12] SCOTTI, A., PONOMAREV, V. Soldagem MIG/MAG - melhor entendimento, melhor desempenho. 1 ed., São Paulo, Artliber Editora, 2008.

[13] NACE. Petroleum and natural gas industries - Materials for use in $\mathrm{H} 2 \mathrm{~S}$ - containing environments in oil and gas production Part 1: General principles for selection of cracking-resistant materials: NACE MRO175/ISO 15156-1:2001/Cor.:2005 (E). U. S. A.: NACE. 2005.

\section{ORCID}

Humberto Vinicius Muñoz Aguirre

Felipe Ribeiro Teixeira

Carlos Alberto Mendes da Mota

Alexandre Saldanha do Nascimento https://orcid.org/0000-0001-8431-7424

https://orcid.org/0000-0002-9945-404X

https://orcid.org/0000-0002-4745-1429

https://orcid.org/0000-0002-0684-3151 